Annales Geophysicae (2004) 22: 4291-4298

SRef-ID: 1432-0576/ag/2004-22-4291

(C) European Geosciences Union 2004

\title{
The Plasmasphere Boundary Layer
}

\author{
D. L. Carpenter ${ }^{1}$ and J. Lemaire ${ }^{2,3}$ \\ ${ }^{1}$ STAR laboratory, Stanford University, Stanford, CA 94 305, USA \\ ${ }^{2}$ CSR-UCL, Louvain, Belgium \\ ${ }^{3}$ IASB, Brussels, Belgium
}

Received: 18 August 2004 - Revised: 29 September 2004 - Accepted: 3 October 2004 - Published: 22 December 2004

\begin{abstract}
As an inner magnetospheric phenomenon the plasmapause region is of interest for a number of reasons, one being the occurrence there of geophysically important interactions between the plasmas of the hot plasma sheet and of the cool plasmasphere. There is a need for a conceptual framework within which to examine and discuss these interactions and their consequences, and we therefore suggest that the plasmapause region be called the Plasmasphere Boundary Layer, or PBL. Such a term has been slow to emerge because of the complexity and variability of the plasma populations that can exist near the plasmapause and because of the variety of criteria used to identify the plasmapause in experimental data. Furthermore, and quite importantly in our view, a substantial obstacle to the consideration of the plasmapause region as a boundary layer has been the longstanding tendency of textbooks on space physics to limit introductory material on the plasmapause phenomenon to zeroth order descriptions in terms of ideal MHD theory, thus implying that the plasmasphere is relatively well understood. A textbook may introduce the concept of shielding of the inner magnetosphere from perturbing convection electric fields, but attention is not usually paid to the variety of physical processes reported to occur in the PBL, such as heating, instabilities, and fast longitudinal flows, processes which must play roles in plasmasphere dynamics in concert with the flow regimes associated with the major dynamo sources of electric fields. We believe that through the use of the PBL concept in future textbook discussions of the plasmasphere and in scientific communications, much progress can be made on longstanding questions about the physics involved in the formation of the plasmapause and in the cycles of erosion and recovery of the plasmasphere.
\end{abstract}

Key words. Magnetospheric physics (plasmasphere; plasma convection; MHD waves and instabilities)

Correspondence to: D. L. Carpenter

(dlc@nova.stanford.edu)

\section{Introduction}

In space, boundary layers tend to form at the interfaces between plasmas that have distinctly different properties, either when considered as fluids or in terms of kinetic descriptions (e.g. Hughes, 1995; Roth et al., 1993; Lakhina et al., 2000). In geospace, such layers tend to be sites of significant wave-particle energy and momentum exchange, crossboundary energy transfer, and particle precipitation into the Earth's ionosphere and atmosphere. Familiar examples are the plasma sheet boundary layer (PSBL) and the low latitude boundary layer (LLBL). Analogous phenomena are a boundary layer in the troposphere just above the ground and one in the ocean, immediately below the sea surface, where air bubbles are engulfed in water within a layer whose thickness depends on the wind velocity and amplitude of the surface waves.

Curiously, the plasmapause region has not been described as a boundary layer, in spite of being observed at locations where the cool $(\approx 1 \mathrm{eV})$ dense $(\approx 400 \mathrm{el} / \mathrm{cc})$ plasmasphere overlaps with, or is otherwise in close proximity to, the hot $(\approx 100 \mathrm{eV}-100 \mathrm{keV})$ tenuous $(\approx 1 \mathrm{el} / \mathrm{cc})$ plasmas of the plasmatrough or the plasmasheet and ring current (e.g. Frank, 1971; Thomsen et al., 1998). Furthermore, the term "boundary layer" has not come into use in spite of the widespread belief in, and at least limited evidence of, a shielding effect whereby nightside juxtapositions of hot and cold plasmas give rise to unbalanced charge densities and therefore polarization electric fields. These fields "shield" the interior of the main plasmasphere from higher-latitude electric fields, as first pointed out by Block (1966) and Karlson $(1970,1971)$ and later discussed by Jaggi and Wolf (1973), Southwood and Wolf (1978), and Wolf (1983), among others.

Given that the plasmapause was first identified in the early 1960s, why has the term "plasmasphere boundary layer" or PBL taken so long to become part of the geospace lexicon? A reviewer of this paper reminds us of the apparent absence in the plasmapause region of the types of well-defined and persistently observable plasma interface characteristics 
associated with the LLBL or PSBL. Instead, there may be substantial spatial and temporal variations in the particular plasma populations that are in juxtaposition in the plasmapause region, as well as a substantial variety in the plasmapause density structure itself. For example, Moldwin et al. (2002) found that only $16 \%$ of the CRRES satellite plasmapause crossings were "classic" isolated steep density gradients, and that a significant density structure was observed outside the innermost steep density gradient on $40 \%$ of the near-equatorial CRRES orbits. Further, one is obliged to consider the rapidity with which a new plasmapause can be formed during increases in disturbance activity, as well as the slowness of some recovery processes, including the development of vestigial (and hence, sometimes multiple) plasmapause effects. Complexities also abound at low altitudes, where the ionosphere appears to play a critical role in the development of fast, latitudinally narrow plasma bulk flows in the plasmapause region. Fortunately, all of these factors, while making the plasmapause region difficult to describe in simple terms, make it all the more challenging scientifically! We hope that the community will accept this view. The term PBL can be of great conceptual value if it is not taken restrictively and is allowed to represent a rich variety of plasma conditions.

An additional reason for the slowness of the PBL concept to develop, and one we wish to emphasize here, is the tendency of introductory discussions of plasmasphere dynamics, in particular those in textbooks, to be limited in scope and to change very little with time, establishing and ultimately perpetuating the impression that the plasmasphere is relatively well understood. Such discussions strongly suggest that the formation of the plasmapause can be well described in the framework of the ideal MHD theory that is often used to approximate the collisionless plasma transport equations. According to this approximation, a newly-developed plasmapause emerges as a topological consequence of the existence of two global electric field distributions and therefore of two plasma flow regimes perpendicular to $\boldsymbol{B}(\boldsymbol{r})$, one induced by the rotating Earth and the other by the solar wind as it impinges upon the magnetosphere (e.g. Parks, 1991). There is, generally, a "stagnation point or line", located in the dusk local time sector, where the total electric field intensity, $\boldsymbol{E}(\boldsymbol{r})$, is equal to zero, and where the ideal MHD convection velocity $\left(\boldsymbol{V}=\boldsymbol{E} \times \boldsymbol{B} / B^{2}\right)$ necessarily vanishes. The stagnation point appears as a mathematical singularity that determines uniquely a "last closed equipotential" or LCE, a separatrix between an inner flow regime that encloses the dipole and an outer one that does not. The difference in the times of exposure of the associated flux tubes to upward fluxes from the underlying ionosphere is offered as an explanation of the reported order-of-magnitude difference in plasma density levels between the inner and outer regions. By inference, the boundary between the two regions represents the plasmapause, either in a developed state or in the process of formation.

Within the framework of this paradigm, the unsteady nature of magnetospheric convection is commonly accounted for by parameterizing the high latitude convection field by some measure of disturbance activity and then tracking the displacements of an assumed initial plasmasphere boundary. Because of the inherent slowness of cold plasma bulk motions in the magnetosphere, the plasmapause is not assumed to coincide with the instantaneous LCE unless a quasi-steady state is reached, in which case the current LCE and plasmapause are expected to coincide. To account for anticipated effects of the hot plasmas of the plasma sheet and ring current on the evolving shape of the plasmasphere, simple modifications of the high latitude potential distribution are commonly introduced.

One can understand the appeal of this paradigm as a pedagogic device. It offers a plausible explanation of the reductions in plasmasphere size during periods of enhanced convection. Crude estimates of the intensity of the solar-windinduced electric field can ostensibly be made, based upon some measure of the distance to a stagnation point in the flow pattern (somewhat by analogy to the way in which the standoff distance to the magnetopause can be estimated). Furthermore, the paradigm is consistent with accumulated evidence that strong plasmasphere erosion effects, leading to outlying or sunward-extending density structures, regularly occur in the afternoon-dusk sector (e.g. Chappell, 1974; Higel and Wu, 1976; Carpenter et al., 1993).

The shortcomings of the "traditional" MHD approach are analogous to the ones students would experience were introductory descriptions of the magnetopause limited to considerations of pressure balance of the solar wind and geomagnetic field. These shortcomings, some of which have been pointed out by Lemaire and Gringauz (1998) in their book on the plasmasphere, stem from: (1) a focus on that region as a body of essentially zero energy particles, and (2) the use of "ad hoc" modifications of the model high-latitude electric field to represent hot/cold plasma interactions in the plasmapause region. These aspects of introductory material have had the unfortunate effect of deflecting the attention of the larger research community away from questions about specific physical processes which may (in concert with the dynamo sources underlying the main flow $\boldsymbol{V}(\boldsymbol{r}, \mathrm{t})$ and the magnetospheric electric field distributions $\mathbf{E}(\mathbf{r}, \mathrm{t}))$ play important roles in cycles of plasmasphere erosion and recovery. Among such processes is the mechanism by which, as an apparent consequence of earthward surges of the hot ion and electron components of the plasma sheet (e.g. Anderson et al., 1991; 1993), fast westward flows within sub-auroral latitude belts are initiated in the pre-midnight sector (e.g. Galperin et al., 1973; Spiro et al., 1979; Anderson et al., 2001; Foster et al., 2002). Another related process is the dynamic shielding of the inner plasmasphere that is believed to take place in conjunction with the earthward displacements of the plasma sheet (e.g. Garner, 2003).

Other PBL processes to be considered include interchange instabilities (e.g. Richmond, 1973; Lemaire, 1974, 1975), intermittent turbulence (Chang, 1999), formation of smallscale and large-scale irregularities (e.g. LeDocq et al., 1994), heating of the plasmapause region (e.g. Brace and Theis, 
1974; Kozyra et al., 1997; Afonin et al., 1997), and energetic particle precipitation (e.g. Rosenberg et al., 1971; Carpenter et al., 1975).

Cautionary notes about the situation have been struck many times over the years. Already in 1967, Dungey (1967) pointed out that available data on the steepness of the plasmapause electron density profile could not be readily explained by simple MHD models, citing the then recently published (and later oft-cited) works of Nishida (1966) and Brice (1967), wherein plasmapause formation was discussed in terms of the separatrix between the electric field induced in the magnetosphere by the solar wind and the field associated with the terrestrial dynamo. Dungey argued: "in reality the flow must be quite variable, being greatly enhanced during disturbed times, and the picture is then less simple. It then seems rather surprising that the knee should be so sharp, but the variable model would predict a patchy density in the region near the knee and this could be the true state".

It should be said that, in practice, modeling of the geoelectric field has gone well beyond the simple approach outlined above in ways that pay increasing attention to experimental data and to the physical processes at work in the coupled magnetosphere-ionosphere system. In earlier work of this kind, semi-empirical electric field models have been developed by Volland $(1973,1975)$ and empirical models based upon observations at synchronous orbit have been developed by Mcllwain $(1974,1986)$. Notable more recent examples of such work are AMIE (Assimilative Mapping of Ionospheric Elecrodynamics) (Richmond, 1992), in which an ionospheric potential pattern is produced from a variety of data sources, and the Rice Convection model (e.g. Spiro et al., 1981; Garner, 2003), in which self consistency is sought among the potential at some high latitude reference, the distribution of magnetospheric electric fields interior to that reference, fieldaligned currents, and the distribution of electric fields and currents in the underlying ionosphere. These important directions of work will hopefully lead to changes in the textbook presentations that have long dominated community perceptions of the plasmasphere and of its geophysical importance. Such changes will be accelerated by further progress in mapping ionospheric electric fields to the region of the magnetosphere where the plasmapause is apparently formed.

In reaction to the situation described above and as a step toward more balanced and penetrating treatments of the physics of the plasmasphere, both in textbooks and in scientific communications in general, we propose that in the future the concept of a Plasmasphere Boundary Layer (PBL) be used as a framework for discussions of the physics and phenomenology of the plasmapause region. The term was briefly introduced in a recent paper on remote sensing the plasmasphere (Carpenter, 2004).

In the following we briefly mention some past and current work pertinent to the concept of a plasmasphere boundary layer.

\section{Examples of research on the PBL}

Support for use of the PBL concept may be found in theoretical and experimental works (some made many years ago) concerning the stability of the plasmapause boundary and of the plasmasphere in general. These works are particularly important in light of the evidence that the plasmapause density profile becomes highly structured in the aftermath of disturbances and during extended recovery periods (e.g. Oya and Ono, 1987; Koons, 1989; Horwitz et al., 1990; Carpenter et al., 1993, 2000; Moldwin et al., 1995).

The occurrence of energy transfer at the PBL has long been evident through ionospheric consequences, such as Stable Auroral Red (SAR) arcs (e.g. Kozyra et al., 1997) and local peaks in ionospheric electron temperature (e.g. Brace and Theis, 1974; Afonin et al., 1997). Substantial energy transfer between the hot electron plasma sheet and the ionosphere has been found to occur in the region of diffuse aurora that extends from the nightside into the dawn sector outside the nominal plasmapause (e.g. Thomsen et al., 1998). The loss to the ionosphere of plasma sheet electrons at energies below $30 \mathrm{keV}$ is believed to be due to wave-particle interactions, but there are ongoing questions about the details of the process (e.g. Lyons, 1997; Koskinen, 1997).

Several recent experimental developments have brought new attention to the PBL. One is the operation since May 2000 of the EUV instrument on the IMAGE satellite, which is providing for the first time global images of the plasmasphere (Sandel et al., 2001, 2003). These images, acquired over multi-hour periods on successive $(\approx 14$-hour) polar orbits, represent quite a new basis for study of plasmasphere erosion and the formation of sunward-extending density plumes, subjects that are in their essence boundary layer phenomena. Another is the use of GPS satellite signals to obtain maps in time series of total electron content (TEC) (Coster et al., 1992) and hence of the time-varying distribution of plasma structures in the ionosphere and overlying plasmasphere (Foster et al., 2002). These maps, in conjunction with scatter radar, are helping to elucidate the complexities of what are now called Sub-Auroral Polarization Streams (SAPS) (Foster et al., 2004), as well as the related phenomenon of latitudinally narrow westward flows called Polarization Jets (PJ) or Sub Auroral Ion Drifts (SAIDs) (e.g. Galperin et al., 1973; Anderson et al., 1991, 1993), all of which develop at the outer limits of the plasmasphere and, as noted above, are apparent consequences of the motions of the equatorial boundaries of the hot ion and electron components of the plasma sheet. The work on SAPS follows upon findings of large concentrations of storm-time electric fields in the dusk sector between $\mathrm{L}=2$ and $\mathrm{L}=4$, based upon CRRES double-probe electric field data (e.g. Wygant et al., 1998; Burke et al., 1998).

Still other recent developments include the use of energetic neutral atom ENA detectors and the FUV instrument on IMAGE (e.g. Mitchell et al., 2001; Mende et al., 2003), the former to investigate the ring current and its location with respect to the plasmasphere and the latter to detect energetic 
proton precipitation. For example, such precipitation appears to be induced as ring current particles encounter a plasmasphere plume and are scattered through the action of electromagnetic ion cyclotron waves (e.g. Spasojević et al., 2004).

The CLUSTER mission has provided its share of new results on PBL structure, reinforcing earlier findings from ISEE-1, CRRES, and synchronous satellites that the plasmapause is far from the one-step "knee" that the LCE scenario would anticipate under "steady-state" geomagnetic activity conditions. The WHISPER and EFW experiments on board the four CLUSTER spacecraft have shown that the plasmapause region is most of the time very structured; small-scale $(<50 \mathrm{~km})$ and large-scale $\left(>0.5 \mathrm{R}_{E}\right)$ density irregularities are generally observed in this intermediate region separating the low density plasmatrough and high density plasmasphere (Darrouzet et al., 2004; Décréau et al., 2004 ${ }^{1}$ ).

To add further complexity to our now rapidly unfolding picture of the plasmasphere and the PBL, Carpenter et al. (2002), using the Radio Plasma Imager (RPI) on IMAGE, have found the PBL to be a "rough" radar target, one that does not return the discrete echo patterns predicted by simple theoretical plasma density models (e.g. Angerami and Thomas, 1964; Lemaire, 1976; Bailey et al., 1990; Green et al., 2000). Furthermore, there is evidence from RPI of a type of density structure that seems to permeate the plasmasphere, namely field-aligned irregularities with cross- $\boldsymbol{B}$ scale sizes from $200 \mathrm{~m}$ to $10 \mathrm{~km}$ and densities within $\approx 10 \%$ of background. These irregularities, preliminary evidence of which was obtained in the era of the ISIS series topside sounders (e.g. Muldrew, 1963, 1969; Loftus et al., 1966), appear to play the important role of guiding sounder-produced waves along the geomagnetic field lines, thus facilitating investigation of plasma density distributions within the natural coordinate system of the magnetosphere (e.g. Reinisch et al., 2001; Fung et al., 2003).

\section{Thoughts about future discussions of the PBL}

What are some of the outstanding questions concerning the PBL? One of the most important but least often asked questions is: what is the physical mechanism or combination of mechanisms by which the plasmapause is formed? Virtually all models, including the most sophisticated ones, tell us where the plasmapause is or should be at a given time, but it is assumed that the plasmapause is formed naturally as an integral effect of the cross- $\boldsymbol{B}$ plasma flows associated with calculated potential distributions. If in these cases an initial plasmasphere configuration is either assumed or taken from observations, there is no explanation of the physical process or processes that gave rise to that initial configuration and the boundary is simply tracked to its later position(s). In

\footnotetext{
${ }^{1}$ Décréau, P. M. E., Le Guirriec, E., Rauch, J. L., Trotignon, J. G., Canu, P., Darrouzet, F., Lemaire, J., Masson, A., Sedgemore, F., and André, M.: Plasmapause formation and density irregularities: Cluster observations in the dusk sector, Adv. Space Sci., submitted, 2004.
}

some sense the ionosphere is given credit for establishing the plasmapause through its capacity to gradually fill flux tubes at all relevant latitudes in the presence of a yes-no condition on whether flux-tube recipients move so as to enclose the dipole.

There is indeed evidence that plasma entrainment by convection electric fields can be a major factor in establishing the differing density levels on either side of an apparent separatrix between flow regimes, an example being the duskside transition between "dayside" and "nightside" plasmatrough density levels (Carpenter et al., 1993). However, there is very little reason to believe that the physics involved in forming the main plasmapause are limited to the adiabatic compression or expansion of plasmas in the neighborhood of a preexisting PBL, and that they do not include local processes involving field-aligned currents, turbulence, and instabilities. For example, as noted above, field-aligned currents driven by pressure gradients in the ring current ion population are found to give rise to intense, poleward directed electric fields in the ionosphere and to associated fast azimuthal bulk plasma flows (e.g. Anderson et al., 2001 and references cited therein; Anderson, 2004). Patchy auroral activity at the low latitude edge of the diffuse aurora in the premidnight sector has been considered as possible evidence of a shear-flow instability associated with fast azimuthal flows (e.g. Kelley, 1986). A belt-like region of the outer plasmasphere tends to become structured in the aftermath of a convection event, such that irregularities with peak to valley ratios of 3:1 and more appear, as well as evidence of MHD turbulence (e.g. Carpenter and Lemaire, 1997 and references cited therein). The plasmapause region itself appears to be a major spawning ground for density irregularities (e.g. Carpenter et al., 1993; Darrouzet et al., 2004), giving the impression that dense plasma elements can be detached from or shed by the plasmasphere, perhaps by analogy to the manner in which icebergs are "calved" from a glacier. Instabilities are clearly at work in this interface region between hot and cold plasmas. Which instabilities are they likely to be, and what particular geophysical roles do they play? These are challenging questions, ones that we hope will draw increasing attention in the future. For our present purposes, we limit ourselves a few remarks about work on interchange motions.

Recent studies of convective wave modes driven by the gravitational and centrifugal forces in stratified plasmas have confirmed that a plasma density distribution in hydrostatic equilibrium can either be stable and oscillate over a range of real frequencies, or may become convectively unstable and expand along magnetic flux tubes when the centrifugal force is enhanced. Newcomb (1961) showed that there are two types of interchange motions, calling them "quasiinterchanges of type 1 and 2 modes".

As discussed by Ferrière et al. (2001), the type 1 quasiinterchange mode is characterized by plasma bulk velocity predominantly transverse to the magnetic field direction; this mode degenerates into "pure interchange" motion when the parallel component of the wave vector, $\boldsymbol{k}$, tends to zero. This asymptotic limit corresponds to Gold's (1959) 
interchange (which has dominated discussions in magnetospheric physics for several decades), in which the shape of magnetic field lines remains unperturbed during the oscillation of the plasma density distribution. (Note that Gold introduced the term "magnetosphere" in that seminal 1959 paper.)

The type 2 quasi-interchange mode is characterized by plasma motion predominantly parallel to the direction of the background magnetic field. This pseudo-parallel mode degenerates into field-aligned convective motion when the parallel component of the wave vector, $\boldsymbol{k}$, tends to zero, i.e. when the plasma motion degenerates into pure field-aligned oscillations or field-aligned translation, such as described by hydrodynamic solutions of the polar wind flow. In general, both type 1 and 2 modes may entail field-line distortions (which were not assumed to occur in most studies that followed Newcomb's work). This is especially true when the ratio of the kinetic pressure over the magnetic pressure is close to unity.

Ferrière et al. (2001) emphasize that because of magneticfield-line curvature, MHD motion of plasma can never be "pure interchange" or "pure translation", but is always a combination of motions across and along the magnetic field lines. André and Lemaire (2004) tested the stability criteria of the quasi-interchange modes against several field distributions of plasma density in the plasmasphere, showing that by taking into account effects of gravity, centrifugal force and magnetic-field-line curvature, the pseudo-translational quasi-interchange mode (type 2) becomes unstable before the type 1 or pseudo-transverse mode. The role in plasmapause formation of quasi-interchange instabilities associated with super-corotational plasma flow in the post-midnight sector has been discussed by Lemaire and Gringauz (1998, pp. 283-284), Lemaire (2001), and Pierrard and Lemaire (2004).

When considering the role of instabilities as factors in plasmapause formation, one must deal with the fact that simple MHD models predict large-scale plasmasphere configurations that are not unlike those that have been observed in situ in the dawn sector and in the outer dayside magnetosphere (e.g. Elphic et al., 1996). However, as remarked above, an MHD model prediction of a plasmasphere configuration does not imply that the evolving properties of the plasmapause density profile have been explained. Furthermore, in the global scale plasmasphere observations from IMAGE there is much that is not predicted by the simple MHD theory (e.g. Spasojević, 2003; Sandel et al., 2003; Goldstein et al., 2004). This should help to stimulate new assessments of the physics of plasmasphere erosion.

A number of fascinating problems come to mind as one considers the PBL and the challenges that it presents. What role does the PBL play in terms of the distribution of global ULF wave activity? How do the dynamos associated with bulk plasma motions interact with one another? The assumption of strict corotation of the inner plasmasphere with the Earth has been shown to be incorrect (e.g. Sandel et al., 2003; Burch et al., 2004), and it is not clear that the Earth imposes strict corotation on the overlying region at high latitudes (e.g. Hines, 1960). How closely coupled are low altitude plasma flows near the polar cap boundary with their counterparts at high altitude near the dayside magnetopause? Near-equatorial electron density measurements beyond synchronous orbit from ISEE 1 (Carpenter et al., 1993) and Geotail (Matsui et al., 1999) suggest that flow of plasma eroded from the plasmasphere into the magnetopause region may at some stages of convection activity be inhibited (e.g. Carpenter et al., 1993).

\section{Suggestions for the textbooks of the future}

We suggest that future introductions to the plasmasphere and its boundary layer begin with the phenomenology of the PBL as revealed by, as examples: global views obtained by the EUV instrument on IMAGE (e.g. Sandel et al., 2003); WHISPER data on density structure near CLUSTER perigee (e.g. Darrouzet et al., 2004; Décréau et al., 2004¹); equatorial electron density data along CRRES satellite orbits (e.g. LeDocq et al., 1994; Carpenter et al., 2000). From these the student should be able to appreciate the huge size of the region, as well as the complexity and variability of its boundaries and internal structure. The traditional MHD paradigm discussed above should then be presented as background, with attention both to the early physical insights that it provided, as well as to the substantial shortcomings noted above. The concept of the PBL should be introduced, including the challenge to understand the as yet poorly understood physical processes at work in the plasmapause region. In this connection, it would not be inappropriate to quote some prescient remarks made in 1978 by Morfill (1978) in an article on the location and formation of the plasmapause:

"It is clear ... that particle drift in the equatorial region of the magnetosphere is not a simple well-defined problem of solving the equation of motion with given force terms, but that irreversible processes (e.g. pitch-angle scattering), bulk properties (e.g. pressure gradients) and perturbation forces (e.g. gravity and centrifugal forces) all play a role in determining the location and stability of the plasmapause." At the end of his article, Morfill speculated that shielding of the convection electric field might be an important factor in explaining differences between various modeling results, and went on to say "If this situation is correct, and a great deal of work, both experimental and theoretical is necessary before we can be certain, then we have yet another fascinating boundary problem in plasma physics to solve."

Acknowledgements. We are grateful to the many colleagues who have shared with us a concern for understanding the physics of the plasmasphere. We are particularly mindful of the recent work of colleagues from the IMAGE and CLUSTER projects, who have provided powerful new observational tools for study of the PBL region. One of us (DLC) would like to dedicate his contribution to this paper to the memory of Chung Park, who passed away in December 2003. In the 1970s, Park's pioneering work on plasmasphere structure and dynamics and on the interchange of thermal plasma between the ionosphere and plasmasphere contributed much to our present day understanding of these phenomena. The work on this 
paper at Stanford was partially supported by IMAGE subcontract 03-08482 from the University of Massachusetts Lowell. At Brussels the work was partially supported by the PRODEX-CLUSTER contract ESA c13127 from BELSPO.

Topical Editor T. Pulkkinen thanks J. Foster and M. Moldwin for their help in evaluating this paper.

\section{References}

Afonin, V. V., Bassolo, V. S., Smilauer, Y., and Lemaire, J.: Motion and erosion of the mightside plasmapause region and of the associated subauroral electron temperature enhancement: COSMOS900 observations, J. Geophys. Res., 102, 2093-2103, 1997.

André, N. and Lemaire, J.: Convective instabilities in the plasmasphere, EGU General Assembly, 2004.

Anderson, P. C.: Subauroral electric fields and magnetospheric convection during the April 2002 geomagnetic storms, Geophys. Res. Lett., 31, L11801, doi:10.1029/2004GL019588, 2004.

Anderson, P. C., Heelis, R. A., and Hanson, W. B.: The ionospheric signatures of rapid subauroral ion drifts, J. Geophys. Res., 96, A4, 5785-5792, 1991.

Anderson, P. C., Hanson, W. B., Heelis, R. A., Craven, J. D., Baker, D. N., and Frank, L. A.: A proposed production model of rapid subauroral ion drifts and their relationship to substorm evolution, J. Geophys. Res., 98, 6069-6078, 1993.

Anderson, P. C., Carpenter, D. L., Tsuruda, K., Mukai, T, and Rich, F. J.: Multisatellite observations of rapid subauroral ion drifts (SAID), J. Geophys. Res., 106, 29 585-29 599, 2001.

André, N., Ondes et instabilités basse-fréquence dans un plasma gyrotrope: Application à l'instabilité d'interchange dans les magnétosphères des planètes géantes, Ph.D. thesis, Université Toulouse III, Paul-Sabatier, 2003.

Angerami, J. J. and Thomas, J. O.: Studies of planetary atmospheres, 1. The distribution of electrons and ions in the earth's exosphere, J. Geophys. Res., 69, 4537-4560, 1964.

Bailey, G. J. and Sellek, R.: A mathematical model of the Earth's plasmasphere and its application to a study of $\mathrm{He}+$ at $\mathrm{L}=3$, Ann. Geophys., 8, 171-190, 1990.

Block, L. P.: On the distribution of electric fields in the magnetosphere, J. Geophys. Res., 71, 855-864, 1966.

Brace, L. H. and Theis, R. F.: The behavior of the plasmapause at midlatitudes: ISIS I Langmuir probe measurements, J. Geophys. Res., 79, 1871-1884, 1974.

Brice, N. M.: Bulk motion of the magnetosphere, J. Geophys. Res., 72, 5193-5211, 1967.

Burch, J. L., Goldstein, J., and Sandel, B. R.: Cause of plasmasphere corotation lag, Geophys. Res. Lett., 31, L05802, doi:10.1029/2003GL019164, 2004.

Burke, W. J., Maynard, N. C., Hagan, M. P., Wolf, R. A., Wilson, G. R., Gentile, L. C., Gussenhoven, M. S., Huang, C. Y., Garner, T. W., and Rich, F. J.: Electrodynamics of the inner magnetosphere observed in the dusk sector by CRRES and DMSP during the magnetic storm of 4-6 June 1991, J. Geophys. Res., 103, 29399 $29418,1998$.

Carpenter, D. L.: Remote sensing the Earth's plasmasphere, Rad. Sci. Bull., 308, 13-29, 2004.

Carpenter, D. L., Foster, J. C., Rosenberg, T. J., and Lanzerotti, L. J.: A subauroral and mid-latitude view of substorm activity, J. Geophys. Res., 80, 4279-4286, 1975.

Carpenter, D. L., Giles, B. L., Chappell, C. R., Décréau, P. M. E., Anderson, R. R., Persoon, A. M., Smith, A. J., Corcuff, Y, and
Canu, P.: Plasmasphere dynamics in the duskside bulge region: a new look at an old topic, J. Geophys. Res., 98 , 19243-19271, 1993.

Carpenter, D. L., Anderson, R. R., Calvert, W., and Moldwin, M. B.: CRRES observations of density cavities inside the plasmasphere, J. Geophys. Res., 105, 23 323-23 338, 2000.

Carpenter, D. L., Spasojević, M. A., Bell, T. F., Inan, U. S., Reinisch, B. W., Galkin, I. A., Benson, R. F., Green, J. L., Fung, S. F., and Boardsen, S. A.: Small-scale fieldaligned plasmasheric density structures inferred from the Radio Plasma Imager on IMAGE, J. Geophys. Res., 107, A9, 1258, doi:10.1029/2001JA009199, 2002.

Carpenter, D. L. and Lemaire, J.: Erosion and recovery of the plasmasphere in the plasmapause region, Space Sci. Rev., 80, 153179, 1997.

Chang, T. S.: Self-organized criticality, multi-fractal spectra, sporadic localized reconnections and intermittent turbulence in space plasmas, Phys. Plasmas, 6, 4137-4145, 1999.

Chappell, C. R.: Detached plasma regions in the magnetosphere, J. Geophys. Res., 79, 1861-1870, 1974.

Coster, A. J., Gaposchkin, E. M., and Thornton, L. E.: Real-time ionospheric monitoring system using GPS, Navigation: J. Inst. Navigation, 39 , 2, 191-204, Summer 1992.

Darrouzet, F, Décréau,P. M. E., De Keyser, J., Masson, A., Gallagher, D. L., Santolik, O., Sandel, B. R., Trotignon, J. G., Rauch, J. L., Le Guirriec, E., Canu, P., Sedgemore, F., André, M., and Lemaire, J. F.: Density structures inside the plasmasphere: Cluster observations, Ann. Geophys., 22, 2577-2585, 2004.

Dungey, J.: The theory of the quiet magnetosphere, in Proceedings of the 1966 Symposium on Solar-Terrestrial Physics, Belgrade, eds. King, J. W. and Newman, W. S., 91-106, 1967.

Elphic, R. C., Weiss, L. A., Thomsen, M. F., McComas, D. J., and Moldwin, M. B.: Evolution of plasmaspheric ions at geosynchronous orbit during times of high geomagnetic activity, Geophys. Res. Lett., 23, 16, 2189-2192, 1996.

Ferrière, K. M., Zimmer, C., and Blanc, M.: Quasi-interchange modes and interchange instability in rotating magnetospheres, $\mathrm{J}$. Geophys. Res., 106, 327-344, 2001.

Foster, J. C., Erickson, P. J., Coster, A. J., Goldstein, J., and Rich, F. J.: Ionospheric signatures of plasma tails, Geophys. Res. Lett., 29, 13, doi:10.1029/2002GL015067, 2002.

Foster, J. C., Coster, A. J., Erickson, P. J., Rich, F. J., and Sandel, B. R.: Stormtime observations of the flux of plasmaspheric ions to the dayside cusp/magnetopause, Geophys. Res. Lett., 31, L08809, doi:10.1029/2004GL020082, 2004.

Frank, L. A.: Relationship of the plasma sheet, ring current, trapping boundary, and plasmapause near the magnetic equator and local midnight, J. Geophys. Res., 76, 2265-2275, 1971.

Fung, S. F., Benson, R. F., Carpenter, D. L., Green, J. L., Jayanti, V., Galkin, I. A., and Reinisch, B. W.: Guided echoes in the magnetosphere: Observations by Radio Plasma Imager on IMAGE, Geophys. Res. Lett., 30, 11, 1589, doi:10.1029/2002GL016531, 2003.

Galperin, Y. I., Ponomarov, Y. N., and Zosinova, A. G.: Direct measurements of ion drift velocity in the upper ionosphere during a magnetic storm, Cosmicheskie Issled., 11 , 273-283, 1973.

Garner, T. W.: Nmerical experiments on the inner magnetospheric electric field, J. Geophys. Res., 108, A10, 1373, doi:10.1029/2003JA010039, 2003.

Gold, T.: Motions in the magnetosphere of the earth, J. Geophys. Res., 61, 1219-1224, 1959. 
Goldstein, J., Sandel, B. R., and Reiff, P. H.: Control of plasmaspheric dynamics by both convection and sub-auroral polarization stream, Geophys. Res. Lett., in press, 2004.

Green, J. L., Benson, R. F., Fung, S. F., Taylor, W. W. L., Boardsen, S. A., Reinisch, B. W., Haines, D. M., Bibl, K., Cheney, G., Galkin, I. A., Huang, X., Myers, S. H., Sales, G. S., Bougeret, J. L., Manning, R., Meyer-Vernet, N., Moncuquet, M., Carpenter, D. L., Gallagher, and Reiff, P. H.: Radio Plasma Imager simulations and measurements, Space Sci. Rev., 91, 361-389, 2000.

Higel, B. and Wu, L.: Electron density and plasmapause characteristics at 6.6 RE: a statistical study of the GEOS 2 relaxation sounder data, J. Geophys. Res., 89, 1583-1601, 1984.

Hines, C.: On the rotation of the polar ionospheric regions, J. Geophys. Res., 65, 141-143, 1960.

Horwitz, J. L., Comfort, R. H., and Chappell, C. R.: A statistical characterization of plasmasphere density structure and boundary locations, J. Geophys. Res., 95, 7937-7947, 1990.

Hughes, W. J.: The magnetopause, magnetotail, and magnetic reconnection, in Introduction to Space Physics, edited by Kivelson, M. G. and Russell, C. T., Cambridge University Press, 227-287, 1995.

Jaggi, R. K. and Wolf, R. A.: Self-consistent calculation of the motion of a sheet of ions in the magnetosphere, J. Geophys. Res., 78, 2852-2866, 1973.

Karlson, E. T.: On the equilibrium of the magnetopause, J.Geophys. Res., 75, 2438-2448, 1970.

Karlson, E. T.: Plasma flow in the magnetosphere, I. A twodimensional model of stationary flow, Cosmic Electrodynamics, 1, 474-495, 1971.

Kelley, M. C.: Intense sheared flow as the origin of large-scale undulations of the edge of the diffuse aurora, J. Geophys. Res., 91, 3225-3230, 1986.

Koons, H. C.: Observations of large-amplitude, whistler mode wave ducts in the outer plasmasphere, J. Geophys. Res., 94, 15393 $15397,1989$.

Koskinen, H. E. J.: Observations of magnetospheric waves and their relation to precipitation, Space Sci. Rev., 80 , 133-152, 1997.

Kozyra, J. U., Nagy, A. F., and Slater, D. W.: High-altitude energy source(s) for stable auroral red arcs, Rev. Geophys., 35, 155-190, 1997.

Lakhina, G. S., Tsurutani, B.T., Kojima, H., and Matsumoto, H.: "Broadband" plasma waves in the boundary layers, J. Geophys. Res., 105, 27 791-27 831, 2000.

LeDocq, M. J., Gurnett, D. A., and Anderson, R. R.: Electron number density fluctuations near the plasmapause observed by CRRES spacecraft, J. Geophys. Res., 99, 23 661-23 671, 1994.

Lemaire, J.: The "Roche-limit" of ionospheric plasma and the formation of the plasmapause, Planet Space Sci., 22, 757-766, 1974.

Lemaire, J.: The mechanisms of formation of the plasmapause, Ann. Geophys., 31, 175-189, 1975.

Lemaire, J.: Rotating ion-exospheres, Planet. Space Sc., 24, 975985, 1976.

Lemaire, J. and Gringauz, K.: The Earth's Plasmasphere, Cambridge University Press, Cambridge, 1998.

Lemaire, J.: The formation of the light ion trough and peeling off the plasmasphere, J. Atmos. Terr. Phys., 63, 1285-1291, 2001.

Loftus, B. T., Van Zandt, T.E., and Calvert, W.: Observations of conjugate ducting by the fixed-frequency topside-sounder satellite, Ann. Geophys., 22, 530-537, 1966.

Lyons, L.: Magnetospheric processes leading to precipitation, Space Sci. Rev., 80, 109-132, 1997.
Matsui, H., Mukai, T., Ohtani, S., Hayashi, K., Elphic, R. C., Thomsen, M. F., and Matsumoto, H.: Cold dense plasma in the outer magnetosphere, J. Geophys. Res., 104, 25 077-25 095, 1999.

McIlwain, C. E.: Substorm injection boundaries, in Magnetospheric Physics, edited by McCormac, B. M., D. Reidel Publishing Co., Dordrecht, Hollard, 143-154, 1974.

McIlwain, C. E.: A Kp dependent equatorial electric field model, Adv. Space Res., 6, 3, 187-197, 1986.

Mende, S. B., Frey, H. U., Immel, T. J., Gerard, J.-C., Hubert, B., and Fuselier, S. A.: Global imaging of proton and electron aurorae in the far ultraviolet, Space Sci. Rev., 109, 211-254, 2003.

Mitchell, D. G., Curtis, C. C., Hamilton, D. C., Voss, H. D., Roelof, E. C., and Brandt, P. C.: Imaging Two Geomagnetic Storms in Energetic Neutral Atoms, Geophys. Res. Lett., 28, 6, 1151-1154, 2001.

Moldwin, M. B., Thomsen, M.F., Bame, S. J., McComas, D. J., and Reeves, G. D.: The fine scale structure of the outer plasmasphere, J. Geophys. Res., 100, 8021-8029, 1995.

Moldwin, M. B., Downward, L., Rassoul, H. K., Amin, R., and Anderson, R. R.: A new model of the location of the plasmapause: CRRES results, J. Geophys. Res., 107, A11, 1339, doi:10.1029/2001JA009211, 2002.

Morfill, G. E.: A review of selected topics in magnetospheric physics, Reports Prog. Phys., 41, 303-394, 1978.

Muldrew, D. G.: Radio propagation along magnetic field-aligned sheets of ionization observed by the Alouette topside sounder, J. Geophys. Res., 68, 5355-5370, 1963.

Muldrew, D. G.: Nonvertical propagation and delayed-echo generation observed by the topside sounders, Proc. IEEE, 57, 10971107, 1969.

Newcomb, W. A.: Convective instability induced by gravity in a plasma with a frozen-in magnetic field, Phys. Fluids, 4, 391-396, 1961

Nishida, A.: Formation of plasmapause, or magnetospheric plasma knee, by the combined action of magnetospheric convection and plasma escape from the tail, J. Geophys. Res., 71, 5669-5679, 1966.

Oya, H. and Ono, T.: Stimulation of plasma waves in the magnetosphere using satellite JIKIKEN (EXOS B) Part II: plasma density across the plasmapause, J. Geomag. and Geoel. 39, 591-607, 1987.

Parks, G. K.: Physics of Space Plasmas, An Introduction, Addison Wesley, 1991.

Pierrard, V. and Lemaire, J. F.: Development of shoulders and plumes in the frame of the interchange instability mechanism for plasmapause formation, Geophys. Res. Lett., 31, L05809, doi:10.1029/2003GL018919, 2004

Reinisch, B. W., Huang, X., Song, P., Sales, G. S., Fung, S. F. Green, J. L., Gallagher, D. L., and Vasyliunas, V. M.: Plasma density distribution along the magnetospheric field: RPI observations from IMAGE, Geophys. Res. Lett., 28, 24, 4521-4524, 2001.

Richmond, A. D.: Self-induced motions of thermal plasma in the magnetosphere and the stability of the plasmapause, Rad. Sci., 8, 1019-1027, 1973.

Richmond, A. D.: Assimilative mapping of ionospheric electrodynamics, Adv. Space Res., 12, 659-668, 1992.

Rosenberg, T. J., Helliwell, R. A., and Katsufrakis, J. P.: Electron precipitation associated with discrete very low frequency emissions, J. Geophys. Res., 76, 8445-8452, 1971.

Roth, M., Evans, D. S., and Lemaire, J.: Theoretical structure of a magnetopsheric plasma boundary: application to the formation 
of discrete auroral arcs, J. Geophys. Res., 98, 11411-11423, 1993.

Sandel, B. R., King, R. A., Forrester, W. T., Gallagher, D. L., Broadfoot, A. L., and Curtis, C. C.: Initial Results from the IMAGE Extreme Ultraviolet Imager, Geophys. Res. Lett., 28, 8, 14391442, 2001.

Sandel, B. R., Goldstein, J., Gallagher, D. L., and Spasojević, M.: Extreme ultraviolet imager observations of the structure and dynamics of the plasmasphere, Space Sci. Rev., 109, 25-46, 2003.

Southwood, D. J. and Wolf, R. A.: An assessment of the role of precipitation in magnetospheric convection. J. Geophys. Res., 83, 5227-5232, 1978.

Spasojević, M., Goldstein, J., Carpenter, D. L., Inan, U. S., Sandel, B. R., Moldwin, M. B., and Reinisch, B. W.: Global response of the plasmasphere to a geomagnetic disturbance, J. Geophys. Res., 108, A9, 1340, doi:10.1029/2003JA009987, 2003.

Spasojević, M., Frey, H. U., Thomsen, M. F., Fuselier, S. A., Gary, S. P., Sandel, B. R., and Inan, U. S.: The link between a detached subauroral proton arc and a plasmapsheric plume, Geophys. Res. Lett., 31 , L04803, doi:10.1029/2003GL018389, 2004.

Spiro, R. W., Heelis, R. A., and Hanson, W. B.: Rapid subauroral ion drifts observed by Atmospheric Explorer C, Geophys. Res. Lett., 6, 657-670, 1979.
Spiro, R. W., Harel, M., Wolf, R. A., and Reiff, P. H.: Quantitative simulation of a magnetospheric substorm, 3. Plasmaspheric electric fields and evolution of the plasmapause, J. Geophys. Res., 86, 2261-2272, 1981.

Thomsen, M. F., McComas, D. J., Borovsky, J. E., and Elphic, R. C.: The magnetospheric trough, in Geospace Mass and Energy Flow: Results From the International Solar-Terrestrial Physics Program, Geophysical Monograph 104, American Geophysical Union, 355-369, 1998.

Volland, H. A.: A semi-empirical model of large-scale magnetospheric electric fields, J. Geophys. Res., 78, 171-180, 1973.

Volland, H. A.: Models of global electric fields within the magnetosphere, Ann. Géophysicae, 31, 159-173, 1975.

Wolf, R. A.: The quasi-static (slow-flow) region of the magnetosphere, in Solar-Terrestrial Physics, Principles and Theoretical Foundations, edited by Carovillano, R. L., and Forbes, J. M., D. Reidel, Dordrecht, 303-329, 1983.

Wygant, J., Rowland, D., Singer, H. J., Temerin, M., Mozer, F., and Hudson, M. K.: Experimental evidence on the role of the large spatial scale electric field in creating the ring current, J. Geophys. Res., 103, 29527-29 544, 1998. 